\title{
Medulloblastomas and primitive neuroectodermal tumors rarely contain polyomavirus DNA sequences ${ }^{1}$
}

\author{
John Y.H. Kim, Igor J. Koralnik, Mark LeFave, Rosalind A. Segal, Luz-Andrea Pfister, \\ and Scott L. Pomeroy ${ }^{2}$ \\ Division of Neuroscience (J.Y.H.K., M.L., S.L.P.), Department of Neurology (S.L.P.), Children's Hospital; \\ Department of Neurology (I.J.K.) and Division of Viral Pathogenesis (I.J.K., L.-A.P.), Beth Israel Deaconess \\ Medical Center; and Department of Pediatric Oncology, Dana-Farber Cancer Institute (J.Y.H.K., R.A.S.), \\ Harvard Medical School, Boston, MA 02115
}

To address the hypothesis that medulloblastoma or supratentorial primitive neuroectodermal tumor (sPNET) can arise through infection by polyomaviruses, we examined genomic DNA isolated from 15 primary medulloblastoma and 5 sPNET biopsy specimens and from 2 medulloblastoma cell lines for the presence of DNA sequences from the polyomaviruses simian virus 40 (SV40), JC virus, and $\mathrm{BK}$ virus. These polyomaviruses have oncogenic potential in animals, and their DNA sequences have been detected in other surveys of various solid tumors, including childhood brain tumors. The tumor DNA samples were analyzed by Southern blot hybridization of polymerase chain reaction products that employed probes designed to detect specific polyomavirus sequences. Neither JC virus nor BK virus DNA sequences were detected in any of the spec-

Received 7 November 2001, accepted 6 February 2002.

${ }^{1}$ This work was supported by National Institutes of Health Grants HD18348 (S.L.P.), NS35701 (S.L.P.), CA09172 (J.Y.H.K.), NS01919 (I.J.K.), and NS37757 (R.A.S.); the David S. Mahoney Center for Neuro-Oncology of the Dana-Farber Cancer Institute (J.Y.H.K.); and the Kyle Mullarkey Medulloblastoma Research Fund at Children's Hospital, Boston, MA.

${ }^{2}$ Address correspondence and reprint requests to Scott L. Pomeroy, Department of Neurology, Children's Hospital, 300 Longwood Ave., Boston, MA 02115.

\footnotetext{
${ }^{3}$ Abbreviations used are as follows: BKV, BK virus; JCV, JC virus; PBS, phosphate-buffered saline; PCS, polymerase chain reaction; SDS, sodium dodecyl sulfate; SSC, saline-sodium citrate; SPNET, supratentorial primitive neuroectodermal tumor; SV40, simian vacuolating virus 40; T-ag, large $\mathrm{T}$ antigen.
}

imens. None of the primary medulloblastoma or sPNET specimens contained SV40 sequences. However, SV40 DNA coding and noncoding sequences were detected in the D283-Med (medulloblastoma) cell line. Immunocytochemical studies of D283-Med revealed nuclear expression of SV40 large T antigen. In contrast to childhood ependymomas and choroid plexus tumors, medulloblastomas and sPNETs infrequently express evidence of polyomavirus infection. Neuro-Oncology 4, 165-170, 2002 (Posted to Neuro-Oncology [serial online], Doc. 01-060, May 1, 2002. URL <neuro-oncology.mc.duke.edu>)

S V40 ${ }^{3}$ is a double-stranded DNA virus in the polyomavirus subfamily of Papovaviridae that was first discovered as a contaminant of live polio vaccines prepared from rhesus monkey kidney cell cultures (Eckhart, 1991; Sweet and Hilleman, 1960). The tumorigenicity of SV40 has raised public health concerns, especially for recipients of contaminated vaccine (Farwell et al., 1979, 1984; Fraumeni et al., 1963, 1970; Heinonen et al., 1973; Innis, 1968; Mortimer et al., 1981).

Outside its natural simian host range, SV40 can transform a variety of nonhost mammalian cell types that are not permissive for viral replication. Neoplastic transformation is mediated by the SV40 T-ag, a 708-amino-acid protein with several functional domains involved in viral replication.

SV40 T-ag exerts its proliferative effects through its interactions with $\mathrm{Rb}$ and P53 and their regulation of cell cycle in a variety of cell lineages (Brinster et al., 1984; DeCaprio et al., 1988; Ludlow et al., 1989, 1990; Saenz Robles et al., 1994; Symonds et al., 1994; Van Dyke 
et al., 1987). SV40 is highly oncogenic in hamster cells, inducing ependymomas and choroid plexus tumors as well as osteosarcomas, mesotheliomas, sarcomas, and several types of lymphomas (Cicala et al., 1992; Diamandopoulous, 1972; Dixon et al., 1982; Kirschstein and Gerber, 1962; Lewis and Martin, 1979; London et al., 1978; Nagashima et al., 1984; Padgett et al., 1977; Uchida et al., 1976).

JCV and BKV are polyomaviruses that are closely related to SV40 and can also act as human pathogens, causing progressive multifocal leukoencephalopathy and interstitial nephritis in immunosuppressed hosts, respectively. Like SV40, JCV and BKV express their own large $\mathrm{T}$ antigens, but their roles in tumorigenesis are less well established. Although SV40-induced brain tumors in animals are generally of glial or ependymal origin, certain JCV strains induce medulloblastoma-like tumors in greater than $90 \%$ of infected Syrian hamsters (Nagashima et al., 1984; Padgett et al., 1977).

For human cancers, SV40 DNA sequences can be detected in most human osteosarcomas and mesotheliomas (Carbone et al., 1994, 1996; Lednicky et al., 1995) and a significant proportion of ependymal and choroid plexus tumors (Bergsagel et al., 1992; Lednicky et al., 1995; Martini et al., 1996). Recently, different groups have reported discordant results regarding the detection of SV40, JCV, and BKV DNA sequences in human medulloblastomas (Hayashi et al., 2001; Huang et al., 1999; Krynska et al., 1999; Weggen et al., 2000).

We examined human medulloblastomas (also known as PNETs of the posterior fossa) and sPNETs for evidence of polyomavirus infection. In contrast to ependymomas and choroid plexus tumors, primary human medulloblastomas and sPNETs do not contain polyomavirus DNA sequences. We detected SV40 DNA sequences and T-ag expression only in the D283-Med medulloblastoma cell line, so we conclude that evidence of polyomavirus infection in human medulloblastomas and sPNETs is rare.

\section{Materials and Methods}

\section{Primary Human Medulloblastoma and sPNET Specimens}

Primary tumor specimens were obtained at the time of initial surgery from 20 pediatric patients treated at Boston Children's Hospital between August 1984 and January 1998 and were examined by a single neuropathologist. Fifteen tumors were classified as medulloblastomas and 5 as sPNETs, according to World Health Organization criteria.

Genomic DNA was purified from the tumor specimens according to established protocols known to isolate low-molecular-weight DNA species, such as episomal viral DNA (Ausubel et al., 1995; Koralnik et al., 1999). DNA preparations were stored at $-20^{\circ} \mathrm{C}$ until time of analysis. Briefly, each frozen tumor specimen was ground to powder with a prechilled mortar and pestle and resuspended in digestion buffer $(100 \mathrm{mM} \mathrm{NaCl}, 10 \mathrm{mM}$ Tris$\mathrm{Cl}$ [pH 8], $25 \mathrm{mM}$ EDTA [pH 8], 0.5\% SDS, $0.1 \mathrm{mg} / \mathrm{ml}$ proteinase K [Sigma, St. Louis, Mo.]). Tumor cell lines were harvested by centrifugation after trypsinization, washed with ice-cold PBS, and then resuspended in digestion buffer. Samples were digested at $50^{\circ} \mathrm{C}$ for 12 to $18 \mathrm{~h}$, then extracted twice with phenol/chloroform/isoamyl alcohol. After centrifugation, DNA-containing aqueous phase material was precipitated with ethanol, washed with 70\% ethanol, air dried, and resuspended in Tris/EDTA buffer ( $\mathrm{pH} 8$ ). Residual RNA was removed by digestion with DNase-free RNase $(1 \mathrm{mg} / \mathrm{ml})$ and $0.1 \%$ SDS at $37^{\circ} \mathrm{C}$ for $1 \mathrm{~h}$ followed by phenol/chloroform/isoamyl alcohol extraction and ethanol precipitation.

\section{PCR}

To identify conserved sequences of the polyomavirus T-ag genes of BKV, JCV, and SV40, we used the oligonucleotide primers PYV.for and PYV.rev according to the methods of Bergsagel et al. (1992). These primers amplify conserved sequences from the $\mathrm{C}$ terminus of the $\mathrm{BKV}$, $\mathrm{JCV}$, and SV40 T-ag genes. Amplification by PCR was performed with thermocycling parameters (PTC-100, MJ Research, Watertown, Mass.) beginning with initial denaturation at $94^{\circ} \mathrm{C}$ for 3 min succeeded by 60 cycles of the following: denaturing step at $94^{\circ} \mathrm{C}$ for $1 \mathrm{~min}$, annealing step at $52^{\circ} \mathrm{C}$ for $1 \mathrm{~min}$, and extension step at $72^{\circ} \mathrm{C}$ for $1 \mathrm{~min}$ with a final extension step, for $5 \mathrm{~min}$.

The PCR reaction products were then analyzed for polyomavirus-specific sequences by Southern blot hybridization (see below). SV40-specific sequences from the upstream noncoding regulatory region were amplified with nested primer pairs: RA3 and RA4, and RA1 and RA2, using previously described conditions (Lednicky et al., 1995).

For JCV-specific T-ag sequences, the primer pair IKTS and IKTAS amplifies a 235-bp fragment in the middle of JCV T-ag, detectable on Southern blot by hybridization with the JCV-specific T-ag probe IKTP (Table 1). The PCR amplification was performed in a 50- $\mu$ l reaction consisting of $10 \mathrm{mM}$ Tris- $\mathrm{HCl}, 50 \mathrm{mM} \mathrm{KCl}, 1.5 \mathrm{mM}$ $\mathrm{MgCl}_{2}, 200 \mu \mathrm{M}$ of each dNTP, 2.5 units of Amplitaq DNA Gold polymerase (PE Biosystems, Foster City, Calif.) or 5 units of Taq DNA polymerase (Roche Molecular Biochemicals, Indianapolis, Ind.), and $25 \mathrm{pmol}$ of each oligonucleotide primer pair. The amplification was carried out with initial denaturing at $94^{\circ} \mathrm{C}$ for 4 min succeeded by 40 cycles of the following: denaturing step at $94^{\circ} \mathrm{C}$ for $30 \mathrm{~s}$, annealing step at $55^{\circ} \mathrm{C}$ for $1 \mathrm{~min}$, and extension step at $72^{\circ} \mathrm{C}$ for $1 \mathrm{~min}$ with a final extension step for $7 \mathrm{~min}$.

Another JCV-specific primer pair, TC1 and TC2, generates a fragment from the $\mathrm{C}$ terminus of the JCV T-ag, detected by hybridization with another JCV-specific T-ag probe (5'-AGTGCAGTTTTCCTGTGTGTCTGCAC-3') (Table 1). The PCR amplification was performed using 45 cycles of the following: denaturing step at $95^{\circ} \mathrm{C}$ for $30 \mathrm{~s}$, annealing step at $52^{\circ} \mathrm{C}$ for $30 \mathrm{~s}$, and extension step at $72^{\circ} \mathrm{C}$ for $30 \mathrm{~s}$ (Krynska et al., 1999).

JCV-specific VP1 gene sequences were amplified with the primer pairs VP11 and VP12 or VP2 and VP3, followed by hybridization with the JCV VP1 probe IKVP1S for VP11/VP12 products (Koralnik et al., 1999) or with another JCV VP1 probe (5'-AGCCAGTGCAGGGCA CCAGC-3') for VP2/VP3 products (Table 1) (Krynska et 
Table 1. PCR primer pairs and Southern blot hybridization probes

$\begin{array}{ll}\text { в-globin primer pair: } \\ \text { PCO3 } & \text { 5'-ACACAACTGTGTTCACTAGC-3' } \\ \text { PCO4 } & \text { 5'-CCACTTGCACCTACTTCAAC-3' }\end{array}$

Polyomavirus T-ag primer pair:

PYV.for 5'-TAGGTGCCAACCTATGGACAGA-3'

PYV.rev 5'-GGAAAGTCTTTAGGGTCTTCTACC-3'

Specific T-ag probes:

BK.probe GAGAATCTGCTGTTGCTTCTT

JC.probe GTTGGGATCCTGTGTTTTCAT

SV.probe ATGTTGAGAGTCAGCAGTAGCC

JCV large T-ag primers:

IKTS 5'-GCCTTGGAAACCAAATGTGAGG-3'

IKTAS 5'-TGTGGATGCTGTCAACCCTTTG-3'

JCV-specific T-ag probe:

IKTP CACATTTTTTGCATTGCTGTGGGTTTTCCTG

JCV large T-ag primers:

TC1 5'-AACCAGCTTTACTTAACAGTTGC-3'

TC2 5'-CCCATTCTTGACTTTCCTAGAG-3'

JCV-specific T-ag probe:

AGTGCAGTTTTCCTGTGTGTCTGCAC

JCV VP1 primers:

VP11 5'-CAGATACATTTGAAAGTGAC-3'

VP12 5'-CCATTAGAGTGCACATTCATC-3'

JCV VP1 probe:

IKVP1S GGACATGCTTCCTTGTTACAGTGTC

JCV VP1 primers:

VP2 5'-TGTGCACTCTAATGGGCAAGC-3'

VP3 5'-CTAGGTACGCCTTGTGCTCTG-3'

JCV VP1 probe:

AGCCAGTGCAGGGCACCAGC

SV40-specific regulatory region nested primers

Internal:

RA1 5'-AATGTGTGTCAGTTAGGGTGTG-3'

RA2 5'-TCCAAAAAAGCCTCCTCACTACTT-3'

External:

RA3 5'-GCGTGACAGCCGGCGCAGCACCA-3'

RA4 5'-GTCCATTAGCTGCAAAGATTCCTC-3'

al., 1999). PCR conditions for primers VP11 and VP12 were identical to those used for primers IKTS and IKTAS. For primers VP2 and VP3, conditions were similar to those for TC1 and TC2, but with an annealing temperature of $52^{\circ} \mathrm{C}$. The integrity of all genomic DNA specimens was confirmed by PCR amplification of the $\beta$-globin gene using previously described conditions and the primer pair PCO3 and PCO4 (Table 1) (Saiki et al., 1985).

\section{Southern Blot Hybridization Analysis}

PCR-amplified DNA products were analyzed by Southern blot hybridization analysis. To identify BKV-specific, JCVspecific, and SV40-specific T-ag sequences, BK.probe, JC.probe, and SV.probe were used, respectively, as previously described (Table 1) (Bergsagel et al., 1992). Detection of JCV-specific sequences with the primer pairs
IKTS/AS, TC1/TC2, VP2/VP3, and VP11/VP12 was performed according to the methods of Koralnik et al. (1999). Briefly, probes were prepared by end-labeling specific oligonucleotides with $\gamma-[32 \mathrm{P}]$ ATP and T4 polynucleotide kinase using standard methods (Ausubel et al., 1995).

PCR reaction products were fractionated by agarose gel electrophoresis (3\% NuSieve: 1\% SeaKem agarose gel; FMC Bioproducts, Rockland, Me.), transferred to a nylon membrane (Duralon UV; Stratagene, La Jolla, Calif.; or Turboblot; Schleicher \& Schuell, Keene, N.H.), and cross-linked with ultraviolet irradiation $(1200 \mathrm{~mJ})$. Blots were prehybridized for $15 \mathrm{~min}$ in Quick-Hyb hybridization solution (Stratagene) at $45^{\circ} \mathrm{C}$ and then hybridized with a minimum of $10^{6} \mathrm{cpm} / \mathrm{ml}$ of ${ }^{32} \mathrm{P}$ end-labeled oligonucleotide probes in Quick-Hyb for at least $4 \mathrm{~h}$ at $42^{\circ} \mathrm{C}$. Hybridized filters were washed to a stringency of $0.2 \times \mathrm{SSC} / 0.1 \% \mathrm{SDS}$ at $42^{\circ} \mathrm{C}$ for BK.probe, JC.probe, and $\mathrm{SV}$.probe. For JCV-specific sequences, blots were washed to a final stringency of $0.5 \times \mathrm{SSC} / 0.2 \% \mathrm{SDS}$ at $45^{\circ} \mathrm{C}$ for IKTS/AS and VP11/VP12, or in $0.1 \times$ SSC/0.1\% SDS at $55^{\circ} \mathrm{C}$ for VP2/VP3 and TC1/TC2 products (Krynska et al., 1999). Washed blots were exposed to a Phosphorimager screen for subsequent image analysis (Molecular Dynamics, Sunnyvale, Calif.).

\section{Cell Culture and Immunocytochemistry}

Immunocytochemical detection of T-ag protein was based on previously described methods of DeCaprio et al. (1988). Human medulloblastoma cell lines Daoy and D283-Med and the COS cell line obtained from the American Type Culture Collection (ATCC, Rockville, Md.) were cultivated in Dulbecco's modified Eagle's medium (Sigma, St. Louis, Mo.) with 10\% heat-inactivated fetal calf serum (Sigma) in humidified $5 \% \mathrm{CO}_{2}$ at $37^{\circ} \mathrm{C}$. The SV40-transformed COS cell line was similarly maintained. Cells were grown on poly-L-lysine-coated coverslips and were fixed in $3.5 \%$ paraformaldehyde in PBS for 10 min at $25^{\circ} \mathrm{C}$, washed 3 times with PBS, extracted with $1 \%$ NP-40 in PBS for 1 min at $25^{\circ} \mathrm{C}$, then dehydrated at $4^{\circ} \mathrm{C}$ in $50 \%$ ethanol for $3 \mathrm{~min}, 100 \%$ ethanol for $5 \mathrm{~min}$, and, finally, $50 \%$ ethanol for $3 \mathrm{~min}$.

For immunocytochemical staining, the anti-T-ag monoclonal antibody (clone Pab419; Oncogene Research Products, Boston, Mass., and courtesy of J. DeCaprio), which recognizes an amino terminal domain of the SV40 T-ag, also present in the SV40 small T-antigen and also crossreactive with JCV T-ag, was used. After fixation and permeabilization, coverslips and tissue sections were washed with PBS and blocked with normal goat serum (4\% in PBS with 0.1\% NP-40; Gibco-BRL, Grand Island, N.Y.). Cells were first incubated with the Pab419 (final concentration $25 \mu \mathrm{g}$ / $\mathrm{ml}$ in blocking buffer) for $1 \mathrm{~h}$ at $37^{\circ} \mathrm{C}$ or overnight at $4^{\circ} \mathrm{C}$.

After cells were washed with PBS, they were incubated with either goat antimouse fluorescein isothiocyanate (FITC)- or Cy2-conjugated secondary antibody (diluted 1:200 in blocking buffer; Jackson ImmunoResearch Laboratories, West Grove, Penn.) for 30 to $60 \mathrm{~min}$ at room temperature. Cells were counterstained with Hoechst $33342(10 \mu \mathrm{M}$ in PBS) for nuclear counterstaining, mounted, and imaged with a NORAN Oz laserscanning confocal microscope (NORAN Instruments, 
Table 2. Detection of polyomavirus DNA sequence

\begin{tabular}{|c|c|c|c|c|c|}
\hline Sample & Tumor type & SV40 & JC & BK & $\beta$-globin \\
\hline Daoy & $\begin{array}{l}\text { Medulloblastoma } \\
\text { cell line }\end{array}$ & - & - & - & + \\
\hline D283-Med & $\begin{array}{l}\text { Medulloblastoma } \\
\text { cell line }\end{array}$ & + & - & - & + \\
\hline 8400 & Medulloblastoma & - & - & - & + \\
\hline 8403 & Medulloblastoma & - & - & - & + \\
\hline 8404 & Medulloblastoma & - & - & - & + \\
\hline 8407 & SPNET & - & - & - & + \\
\hline 8503 & Medulloblastoma & - & - & - & + \\
\hline 8516 & Medulloblastoma & - & - & - & + \\
\hline 8525 & Medulloblastoma & - & - & - & + \\
\hline 8603 & sPNET & - & - & - & + \\
\hline 8611 & Medulloblastoma & - & - & - & + \\
\hline 8615 & sPNET & - & - & - & + \\
\hline 8618 & Medulloblastoma & - & - & - & + \\
\hline 8702 & sPNET & - & - & - & + \\
\hline 8705 & sPNET & - & - & - & + \\
\hline 8719 & Medulloblastoma & - & - & - & + \\
\hline N5011 & Medulloblastoma & - & - & - & + \\
\hline N5017 & Medulloblastoma & - & - & - & + \\
\hline N5032 & Medulloblastoma & - & - & - & + \\
\hline N5062 & Medulloblastoma & - & - & - & + \\
\hline N5064 & Medulloblastoma & - & - & - & + \\
\hline N5072 & Medulloblastoma & - & - & - & + \\
\hline
\end{tabular}

Middleton, Wis.). Formalin-fixed, paraffin-embedded sections of 4 primary medulloblastoma tumors were also processed similarly after deparaffinization in xylene and rehydration through ethanol series. Positive control experiments were conducted on COS cell cultures and formalin-fixed, paraffin-embedded sections of SV40infected monkey tissues. Negative control experiments were performed by omitting the PAb419 primary antibody (secondary antibody alone) or by using unrelated primary monoclonal antibodies (data not shown).

\section{Results}

\section{Polyomavirus Coding Sequences in Medulloblastomas and sPNETs and SV40 Noncoding Sequences in D283-Med}

Genomic DNA from 15 primary medulloblastomas, 2 medulloblastoma cell lines, and 5 sPNET was amplified for polyomavirus T-ag and screened by hybridization for specific SV40, JCV, or BKV sequences. The integrity of all DNA samples was tested by amplifying a segment of the $\beta$-globin gene (Saiki et al., 1985). Only those samples with intact $\beta$-globin sequences were examined for the presence of polyomavirus T-ag sequences independently in 2 separate laboratories (S.L.P. and I.J.K.) to verify the findings. None of the primary medulloblastomas or sPNET DNA samples contained T-ag sequences from any of the polyomaviruses (Table 2).

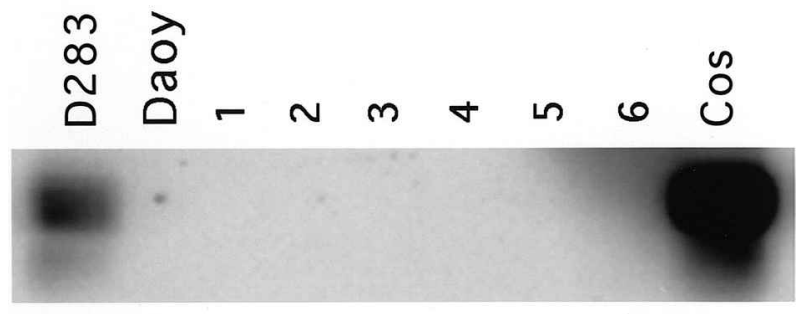

Fig. 1. Southern blot analysis of PCR-amplified DNA from primary human medulloblastomas and cell lines. DNA from medulloblastoma cell line D283-Med contains SV40-specific T-ag sequences, whereas Daoy DNA does not and neither do any primary human medulloblastoma and SPNET specimens (numbered 1-6). Positive control COS cells contain strongly positive SV40 T-ag DNA.

To control for primer selection, we performed additional experiments using different primer pairs for regions in the middle and in the $\mathrm{C}$ terminus of the $\mathrm{T}$-ag genes, the results of which were uniformly negative. Amplification of the major capsid protein VP1 sequences for JCV has been shown to be reliable for the detection of this virus in immunosuppressed individuals (Koralnik et al., 1999). Amplification with 2 different primer pairs spanning the $\mathrm{N}$ terminus of VP1 was negative in all primary medulloblastomas and sPNETs. As shown in Fig. 1, the only evidence of SV40 T-ag was detected in the D283-Med cell line.

To determine whether T-ag expression was an isolated phenomenon, we sought additional polyomavirus sequences. The sequence of an upstream regulatory region of SV40 varies among different viral strains (Lednicky et al., 1995). PCR amplification with nested primer pairs specific for the regulatory region revealed that the D283Med, but not the Daoy cell line, contains SV40 noncoding DNA sequences. Primary medulloblastomas and sPNETs were uniformly negative. These results confirm that D283-Med cells contain not only SV40 T-ag gene sequences, but also noncoding SV40 DNA sequences.

\section{SV40 T-ag Protein Expression}

Immunochemical evidence of T-ag protein was detected in the nuclei of D283-Med cells, as shown in Fig. 2. Neither the Daoy medulloblastoma cell line nor 4 primary medulloblastoma tumors revealed T-ag expression, with SV40-infected tissues being used as a positive control. These results suggest that polyomavirus T-ag may contribute to the immortalized phenotype of D283-Med.

To determine whether the positive results in D283Med were a result of contamination within our lab, we obtained a second lot of cryopreserved D283-Med from the ATCC. Experiments were repeated in separate facilities, using separate reagents, which confirmed the presence of SV40 DNA and T-ag protein. Parallel control experiments were consistently negative.

\section{Discussion}

We did not find evidence for oncogenic polyomaviruses in primary human medulloblastomas or sPNETs. Although 

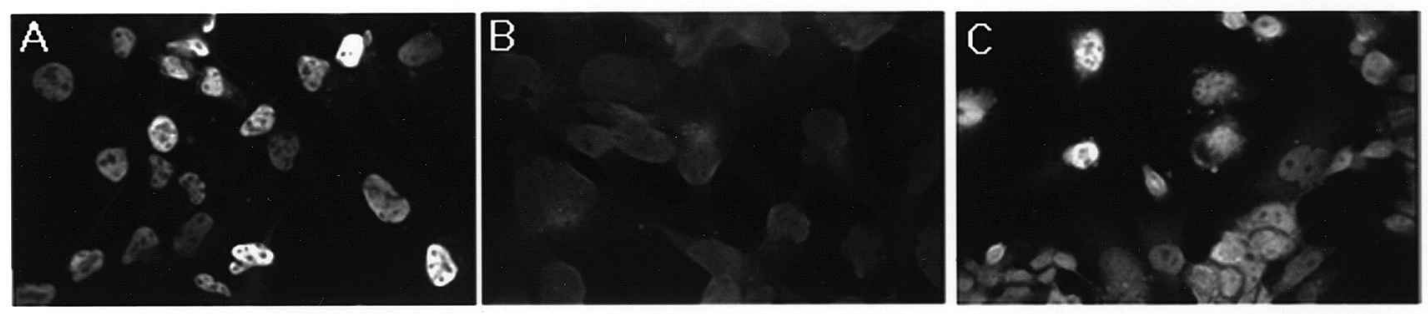

Fig. 2. Immunofluorescent staining for SV40 T-ag. A. Positive control COS cells constitutively expressing nuclear T-ag, as shown by positive immunostaining with anti-T-ag monoclonal antibody (PAb 419) and secondary fluorescein-conjugated antibody. All samples were viewed with a 40× Nikon objective, NORAN confocal microscope. B. The human medulloblastoma cell line, Daoy, does not express SV40 T-ag. C. Another human medulloblastoma cell line, D283-Med, displays nuclear SV40 T-ag.

the presence of T-ag in D283-Med is notable, possibly contributing to its phenotype, we cannot determine whether the virus was present at the time the original tumor was originally isolated or whether it subsequently was introduced during derivation of the cell line. We conclude that SV40 can be found only rarely in human medulloblastomas. Furthermore, although JCV can induce medulloblastomas in hamsters, we do not find evidence for JCV or BKV in the human disease.

Our results essentially concur with a large German report that identified SV40 DNA sequences in only 2 of 116 medulloblastomas (2\%), and no JCV and BKV sequences when similar PCR methods and primers were used (Weggen et al., 2000). In another European study that included 17 medulloblastomas, SV40 DNA sequences were detected in $5(29 \%)$ specimens, BKV sequences in $1(6 \%)$, and JCV sequences in none with PCR amplification and Southern methods (Huang et al., 1999). A Japanese group described negative results for JCV sequences in 8 medulloblastoma specimens; 6 by PCR amplification and Southern blotting, and 2 by in situ hybridization and immunostaining (Hayashi et al. 2001). In contrast, North American investigators reported that 22 of $23(96 \%)$ medulloblastomas contained JCV DNA sequences, and 5 of $23(22 \%)$ also contained SV40 sequences. In their study, JCV T-ag was also detected immunohistochemically in 4 of $16(25 \%)$ samples (Krynska et al., 1999). Our negative results in 15 North American patient specimens are significantly less than predicted by the conclusions of Krynska et al. (2-sided $P<0.0001$ and $P=0.07$ for JCV and SV40, respectively). One possible explanation is that geographic factors account for the striking variability of SV40, JCV, and BKV detection reported in different medulloblastoma series. Accordingly, our findings do not support a significant incidence of polyomavirus infection in medulloblastomas in the northeastern United States.

Several groups have reported the presence of SV40 T-ag in a variety of human cancers and suggested a viral role in their tumorigenesis (Bergsagel et al., 1992; Carbone et al., 1994, 1996; Lednicky et al., 1995; Martini et al., 1996). Recent epidemiological studies of the contamination of polio vaccines with SV40, which occurred in the late 1950s and early 1960s, conclude that recipients of the contaminated vaccines did not display a highly increased risk for carcinogenesis (Fraumeni et al., 1963, 1970; Mortimer et al., 1981). Several studies suggested, however, a small measurable increase in the frequency of nervous system cancers, especially among the offspring of women vaccinated during pregnancy (Innis, 1968; Heinonen et al., 1973; Farwell et al., 1979,1984). Our results indicate that evidence of infection with SV40 or other polyomaviruses is not common in human medulloblastoma or sPNET, and therefore does not appear to be a major factor in their tumorigenesis.

\section{Acknowledgments}

The authors thank James DeCaprio for the gift of the Pab419 antibody, Sommala Khoxayo for technical assistance, and John A. Lednicky and Robert L. Garcea for advice and reading of the manuscript.

\section{References}

Ausubel, F.M., Brent, R., Kingston, R.E., Moore, D.D., Seidman, J.G., Smith, J.A., and Struhl, K. (Eds.) (1995) Preparation of genomic DNA. In: Short Protocols in Molecular Biology. Third edition. New York: Wiley. pp. 2.2.12.2.2; 6.4.6-6.4.7.

Bergsagel, D.J., Finegold, M.J., Butel, J.S., Kupsky, W.J., and Garcea, R.L. (1992) DNA sequences similar to those of simian virus 40 in ependymomas and choroid plexus tumors of childhood. N. Engl. J. Med. 326, 988-993.

Brinster, R.L., Chen, H.Y., Messing, A., van Dyke, T., Levine, A.J., and Palmiter, R.D. (1984) Transgenic mice harboring SV40 T-antigen genes develop characteristic brain tumors. Cell 37, 367-379.

Carbone, M., Pass, H.I., Rizzo, P., Marinetti, M.R., DiMuzio, M., Mew, D.J.Y.,
Levine, A.S., and Procopio, A. (1994) Simian virus 40-like DNA sequences in human pleural mesothelioma. Oncogene 9, 1781-1790.

Carbone, M., Rizzo, P., Procopio, A., Giuliano, M., Pass, H.I., Gebhardt, M.C., Mangham, C., Hansen, M., Malkin, D.F., Bushart, G., Pompetti, F., Picci, P., Levine, A.S., Bergsagel, J.D., and Garcea, R.L. (1996) SV40-like sequences in human bone tumors. Oncogene 13, 527-535.

Cicala, C., Pompetti, F., Nguyen, P., Dixon, K., Levine, A.S., and Carbone, M. (1992) SV40 small T deletion mutants preferentially transform mononuclear phagocytes and B lymphocytes in vivo. Virology 190, 475-479.

DeCaprio, J.A., Ludlow, J.W., Figge, J., Shew, J.-Y., Huang, C.-M., Lee, W.-H., Marsilio, E., Paucha, E., and Livingston, D.M. (1988) SV40 large tumor 
antigen forms a specific complex with the product of the retinoblastoma susceptibility gene. Cell 54, 275-283.

Diamandopoulous, G.T. (1972) Leukemia, lymphoma, and osteosarcomainduced in the Syrian golden hamster by simian virus 40 . Science 176, 173-175.

Dixon, K., Ryder, B.J., and Burch-Jaffe, E. (1982) Enhanced metastasis of tumours induced by a SV40 small T deletion mutant. Nature 296, 672-675.

Eckhart, W. (1991) Polyomavirinae and their replication. In: Fields, B.N., and Knipe, D.M. (Eds.), Fundamental Virology. Second edition. New York: Raven Press. pp. 727-741.

Farwell, J.R., Dohrmann, G.J., Marrett, L.D., and Meigs, J.W. (1979) Effect of SV40 virus-contaminated polio vaccine on the incidence and type of CNS neoplasms in children: A population-basedstudy. Trans. Am. Neurol. Assoc. 104, 261-264.

Farwell, J.R., Dohrmann, G.J., and Flannery, J.T. (1984) Medulloblastoma in childhood: An epidemiological study. J. Neurosurg. 61, 657-664.

Fraumeni, J.F., Jr., Ederer, F., and Miller, R.W. (1963) An evaluation of the carcinogenicity of simian virus 40 in man. J. Am. Med. Assoc. 185, 713-718.

Fraumeni, J.F., Jr., Stark, C.R., Gold, E., and Lepow, M.L. (1970) Simian virus 40 in polio vaccine: Follow-up of newborn recipients. Science 167, 59-60.

Hayashi, H., Endo, S., Suzuki, S., Tanaka, S., Sawa, H., Ozaki, Y., Sawamura, Y., and Nagashima, K. (2001) JC virus large T protein transforms rodent cells but is not involved in human medulloblastoma. Neuropathology 21, 129-137.

Heinonen, O.P., Shapiro, S., Monson, R.R., Hartz, S.C., Rosenberg, L., and Slone, D. (1973) Immunization during pregnancy against poliomyelitis and influenza in relation to childhood malignancy. Int. J. Epidemiol. 2, 229-235.

Huang, H., Reis, R.K., Yonekawa, Y., Lopes, J.M., Kleihues, P., and Ohgaki, H. (1999) Identification in human brain tumors of DNA sequences specific for SV40 large T antigen. Brain Pathol. 9, 33-42.

Innis, M.D. (1968) Oncogenesis and poliomyelitisvaccine. Nature 219, 972-973.

Kirschstein, R.L., and Gerber, P. (1962) Ependymomas produced after intracerebral inoculation of SV40 into newborn hamsters. Nature 195, 299-300.

Koralnik, I.J., Boden, D., Mai, V.X., Lord, C.I., and Letvin, N.L. (1999) JC virus DNA load in patients with and without progressive multifocal leukoencephalopathy. Neurology 52, 253-260.

Krynska, B., Del Valle, L., Croul, S., Gordon, J., Katsetos, C.D., Carbone, M., Giordano, A., and Khalili, K. (1999) Detection of human neurotropic JC virus DNA sequences and expression of the viral oncogenic protein in pediatric medulloblastomas. Proc. Natl. Acad. Sci. U.S.A. 96, 11519-11524.

Lednicky, J.A., Garcea, R.L., Bergsagel, D.J., and Butel, J.S. (1995) Natural simian virus 40 strains are present in human choroid plexus and ependymoma tumors. Virology 212, 710-717.

Lewis, A.M., Jr., and Martin, R.G. (1979) Oncogenicity of simian virus 40 deletion mutants that induce altered 17-kilodalton t-proteins. Proc. Natl. Acad. Sci. U.S.A. 76, 4299-4302.

London, W.T., Houff, S.A., Madden, D.L., Fuccillo, D.A., Gravell, M., Wallen, W.C., Palmer, A.E., and Sever, J.L. (1978) Brain tumors in owl monkeys inoculated with a human polyomavirus (JC virus). Science 201, 1246-1249. Ludlow, J.W., DeCaprio, J.A., Huang, C.-M., Lee, W.-H., Paucha, E., and Liv- ingston, D.M. (1989) SV40 large T antigen binds preferentially to an underphosphorylated member of the retinoblastoma susceptibility gene product family. Cell 56, 57-65.

Ludlow, J.W., Shon, J., Pipas, J.M., Livingston, D.M., and DeCaprio, J.A. (1990) The retinoblastoma susceptibility gene product undergoes cell cycle-dependentdephosphorylation and binding to and release from SV40 large T. Cell 60, 387-396.

Martini, F., laccheri, L., Lazzarin, L., Carinci, P., Corallini, A., Gerosa, M., Iuzzolino, P., Barbanti-Brodano, G., and Tognon, M. (1996) SV40 early region and large $T$ antigen in human brain tumors, peripheral blood cells, and sperm fluids from healthy individuals. Cancer Res. 56, 4820-4825

Mortimer, E.A., Jr., Lepow, M.L., Gold, E., Robbins, F.C., Burton, G.J., and Fraumeni, J.F., Jr. (1981) Long-term follow-up of persons inadvertently inoculated with SV40 as neonates. N. Engl. J. Med. 305, 1517-1518

Nagashima, K., Yasui, K., Kimura, J., Washizu, M., Yamaguchi, K., and Mori, W. (1984) Induction of brain tumors by a newly isolated JC virus (Tokyo1 strain). Am. J. Pathol. 116, 455-463.

Padgett, B.L., Walker, D.L., ZuRhein, G.M., and Varakis, J.N. (1977) Differential neurooncogenicity of strains of JC virus, a human polyoma virus, in newborn Syrian hamsters. Cancer Res. 37, 718-720.

Saiki, R.K., Scharf, S., Faloona, F., Mullis, K.B., Horn, G.T., Erlich, H.A., and Arnheim, N. (1985) Enzymatic amplification of $\beta$-globin genomic sequences and restriction site analysis for diagnosis of sickle cell anemia. Science $\mathbf{2 3 0}$, 1350-1354.

Saenz Robles, M.T., Symonds, H., Chen, J., and van Dyke, T. (1994) Induction versus progression of brain tumor development: Differential functions for the pRb- and p53-targeting domains of simian virus $40 \mathrm{~T}$ antigen. Mol. Cell. Biol. 14, 2686-2698.

Sweet, B.H., and Hilleman, M.R. (1960) The vacuolating virus, S.V.40. Proc. Soc. Exp. Biol. Med. 105, 420-427.

Symonds, H., Krall, L., Remington, L., Saenz Robles, M., Lowe, S., Jacks, T., and Van Dyke, T. (1994) p53-dependent apoptosis suppresses tumor growth and progression in vivo. Cell 78, 703-711.

Uchida, S., Watanabe, S., Aizawa, T., Kato, K., Furuno, A., and Muto, T. (1976) Induction of papillary ependymomas and insulinomas in the syrian golden hamster by BK virus, a human papovavirus. Gann. 67, 857-865.

Van Dyke, T.A., Finlay, C., Miller, D., Marks, J., Lozano, G., and Levine, A.J. (1987) Relationship between simian virus 40 large tumor antigen expression and tumor formation in transgenic mice. J. Virol. 61, 2029-2032.

Weggen, S., Bayer, T.A., von Deimling, A., Reifenberger, G., von Schweinitz, D., Wiestler, O.D., and Pietsch, T. (2000) Low frequency of SV40, JC and BK polyomavirus sequences in human medulloblastomas, meningiomas and ependymomas. Brain Pathol. 10, 85-92. 